\title{
Dual Active Bridge (DAB) DC-DC converter for multilevel propulsion converters for electrical multiple units (EMU)
}

\author{
Marek Adamowicz ${ }^{1,2, *}$, Zbigniew Krzemiński ${ }^{2,3}$, and Pawet Stec ${ }^{4}$ \\ ${ }^{1}$ Gdansk University of Technology, Faculty of Electrical and Control Engineering, ul. Narutowicza 11/12, 80-233, Gdansk, Poland \\ ${ }^{2}$ H. Cegielski-Energocentrum Sp. z o.o., ul. 28 Czerwca 1956 r. 223/229, 61-485, Poznań, Poland \\ ${ }^{3}$ MMB Drives Sp. z o.o., ul. Maszynowa 26, 80-298, Gdańsk, Poland \\ ${ }^{4}$ PESA Bydgoszcz S.A., R \& D Department, ul. Zygmunta Augusta 11, 85-082, Bydgoszcz, Poland
}

\begin{abstract}
Semiconductor power devices made from silicon carbide (SiC) reached a level of technology enabling their widespread use in power converters. Two different approaches to implementation of modern traction converters in electric multiple units (EMU) have been presented in recent years: (i) $3.3-\mathrm{kV} \mathrm{SiC}$ MOSFET-based three-level PWM inverter with regenerative braking and (ii) 6.5-kV IGBT-based fourquadrant power electronic traction transformer (PETT). The former has successfully reached optimized dimensions and efficiency but still requires a bulky line frequency transformer for multisystem applications. The latter characterizes inherent galvanic isolation from AC traction, which is realized by cascaded system of power electronic cells containing medium frequency transformers (MFT). The downsizing of the $6.5-\mathrm{kV}$ IGBT-based cells is, however, problematic. The present paper proposes a different approach, that involves the use of a fast switching 1.2-kV SiC MOSFETS. The SiC-based PETT proposed in the paper is dedicated first for the DC traction. For multi-system application the input voltage of the proposed PETT can be adjusted using weight-optimized adjusting autotransformer. Thanks to utilization of fast-switching SiCbased power modules the weight and size of the power electronic cells can be optimized in a convenient way.
\end{abstract}

\section{Introduction}

Modern semiconductor devices allow realization of traction power converters with minimized weight and size, and high efficiency [1]. Silicon carbide (SiC) semiconductor material is treated as a direct successor to silicon $(\mathrm{Si})$. The high breakdown electric field, low specific on-resistance, high operating frequency and high junction temperature of $\mathrm{SiC}$ transistors are beneficial for the efficiency, power density, specific power and reliability of traction power converters. SiC Metal Oxide Field Effect Transistors (SiC MOSFETs) enable lower system costs by providing the ability for increasing power density and frequency of operation, thereby reducing the volume and weight of the power converter [2]. To increase the number of applications, that $\mathrm{SiC}$ MOSFETs can serve, manufacturers of these devices have extended their capability to higher voltages [3], [4]. A megawatt-scale traction inverter using $3.3 \mathrm{kV} \mathrm{SiC}$ MOSFETs, made by Mitsubishi company, has been successfully used in Japanese EMU trains powered from $1500 \mathrm{~V}$ DC traction. The three-level PWM inverter with regenerative braking using $1.5 \mathrm{kA} \mathrm{SiC} \mathrm{MOSFETs} \mathrm{has}$ been applied to Shinkansen train, providing a $2.5 \mathrm{kV}$ AC voltage for the group of $305 \mathrm{~kW}$ power, self-cooling traction motors, operating in parallel.
The $3.3 \mathrm{kV} \mathrm{SiC}$-based power modules have over $70 \%$ less switching losses than Si-based GTO thyristors used earlier. As it was reported in [5], the use of $\mathrm{SiC}$ modules in N700 Shinkansen bullet train reduced the size and weight of its inverter system by approximately $55 \%$ and $35 \%$, respectively, compared to inverters using GTOs.

In the $3 \mathrm{kV}$ DC traction network, either $6.5 \mathrm{kV}$ IGBTbased two-level inverters or multilevel inverters using 3.3.kV switches can be used. Multilevel inverters characterize lower $\mathrm{dv} / \mathrm{dt}$ slew rates than two-level inverters and can operate at higher resulting frequency without augmented electromagnetic interference (EMI) emission. Multisystem EMUs operated in Europe within different traction systems: $3 \mathrm{kV} \mathrm{DC}, 25 \mathrm{kV} / 50 \mathrm{~Hz}$ and $15 \mathrm{kV} / 16.7 \mathrm{~Hz}$ have on-board power distribution systems, which are reconfigured on-line [6] by using high voltage switchboards and multi-winding traction transformers. Three main goals of multi-system EMU design are selected. They are time to reach full speed operation of the train (acceleration improvement), energy saving and weight and dimension reduction of the electrical equipment. The limiting factor for the EMU train's acceleration can be overcome by increasing the number of powered axles, which, however, binds with increasing cost of the system. More serious limitations apply to electrical equipment downsizing problem. The low

\footnotetext{
* Corresponding author: marek.adamowicz@pg.edu.pl
} 
frequency transformer (LFT) is the heaviest and bulky constituent of the multi-system rolling stock and it represents the worst efficiency between different main components of traction drive. Traditionally, LFT occupies $12 \%$ of the weight and volume of rail vehicles. Nevertheless it is $82 \%$ smaller than its infrastructure onground counterpart. Today, one the most important evolution to be realized on traction transformer is the power electronics on-board traction transformer (PETT) [7], [8]. The power electronics on-board transformer combine several high voltage AC-AC converters connected in series and directly connected to catenary, several high-frequency transformers (HFT) providing galvanic isolation and several rectifiers, each connected to the secondary side of one high frequency transformer, which supplies usual DC-link or several independent DC-links used by other on-board converters. On-board PETT provides control functionality which are far beyond conventional LFT capabilities. Modular approach can cope with any grid voltage by increasing the number of cascaded cells. Cascaded full-bridge topology is actually the most popular solution for constructing PETT prototypes. However the connection of full-bridge converters at the high-voltage side, e.g. $25 \mathrm{kV}$ or $15 \mathrm{kV}$ is still a challenge. Unlike full-bridge converters, the three-level neutral point clamped (NPC) converter [5] does not provide modularity. Bi-directional three-level NPC converters cannot be scaled to $15 \mathrm{kV}$ or $25 \mathrm{kV}$ voltage level, except for using of direct series connection of power semiconductors [9].

The world's first PETT installed in the Ee 933-Type shunting locomotive fed from $15-\mathrm{kV} / 16.7-\mathrm{Hz}$ traction has shown in [10]. The PETT system described in [10] is constructed from isolated AC-DC-DC cells, which includes resonant DC-DC converters. Each powerelectronic cell is made of two types of power modules: high voltage and low voltage. Application of different voltage level subassemblies causes increased complexity of the system. The high voltage PEBBs consist of bulky $6.5 \mathrm{kV}$ IGBTs connected to $3.6 \mathrm{kV}$ dc-link, while the faster, low voltage $3.3 \mathrm{kV}$ IGBTs are connected to dclink of the propulsion converter. Very slow speed of high voltage IGBTs limits the operating frequency of HFTs. The PETT system in [10] needs, at minimum, $\mathrm{N}=8$ cells. Selection of $6.5-\mathrm{kV}$ IGBTs for converter design also entails unfavourably high cost of capacitors, inductive components, protection devices and the whole system.

The present paper aims the development of another type of isolated modular traction converter for multisystem EMUs [11]. The essence of the proposed approach is to apply $1.2 \mathrm{kV} \mathrm{SiC}$ power modules to construct small-size and fast-switching PETT operating at full DC traction voltage and partial AC traction $(25 \mathrm{kV}$ or $15 \mathrm{kV}$ ) voltage.

For AC traction application the inherent galvanic isolation of the proposed converter need not be duplicated by bulky line-frequency transformer. Instead, a weight-optimized autotransformer can be used for adjusting the input voltage of the converter. First of all, the basic topology which can be directly connected to DC traction grid is presented. For multi-system applications the whole system of PETT with LF autotransformer is proposed. In Section II the very recent achievements in the power electronic transformer technology are described. Section III shows a SiC-based Dual Active Bridge (DAB) DC-DC converter as the key component of SiC-based PETT. Experimental results of the proposed $\mathrm{SiC}$-based $\mathrm{DAB}$ converter are given in section IV. Discussion and conclusions are covered in section $\mathrm{V}$.

\section{Recent achievements in power electronic transformer (PET) industrial applications}

Electrical drives consume $64 \%$ of all electricity used in industry. Use of frequency converters with electronic speed control providing recuperation of brake energy into the system leads to save energy and increase efficiency. Many medium voltage (MV) variable speed drive applications need one or two LF transformers matching voltage levels in the system. In the oil industry, typical offshore installations of megawatt scale electric submersible pumps (ESP) have step down transformer that supplies low voltage variable speed drive (VSD) and step up transformer providing MV for the high horsepower (above 1000 HP) ESP motor. With the power electronic transformer (PET), supply line voltage up to $6.6 \mathrm{kV}$ does not need to be stepped down, furthermore is no requirement for a multi-tap step up transformer as the VSD can provide the required medium voltage required for the ESP motor. The removal of LF transformers has reduced the space and weight of the surface electrical equipment, which has a significant influence on the size and load bearing capabilities of new installations [12].

Application of PET topology to industrial drives leads to several advantages such as: (i) power scalability, (ii) ability to shape output voltage with significantly reduced harmonic content and, hence, operation with small size passive filter and (iv) ease of maintenance and inspections. In [12] the benefits of application of PET in the oil industry has been presented. The typical state-ofthe-art surface equipment containing two low-frequency transformers occupies significant deck space, of about 10 $\mathrm{m}^{2}$. The PET-based VSD doesn't need any additional transformers and makes it possible to obtain advantageously smaller footprint. Hence, it gives possibility to upgrade the surface equipment in terms of higher power or possibility of installing additional drive on the same used surface.

The first PET-based VSD has been installed in Saudi Aramco fields in 2014 [12], [13]. The overall scheme of IGBT-based 3.3kV/3.3kV PET is shown in Fig. 1 [13]. The PET topology features isolated dual active bridge (DAB) DC-DC converter technology [14] with a PWM multilevel cascaded full-bridge rectifier at the input and PWM multilevel cascaded full-bridge inverter at the output of the system [15]. Each phase leg of the PET from Fig. 1 consists of 3 cascaded cells. The full-bridge converters in Fig. 1. are constructed from 1.7kV IGBTs and DAB DC-DC converters utilize 1:1 HFTs. The use 
of universal modules on the primary and secondary side reduces complexity of the system and makes easier maintenance of the system and reduces production costs when compared to $15 \mathrm{kV}$ PETT from [10].

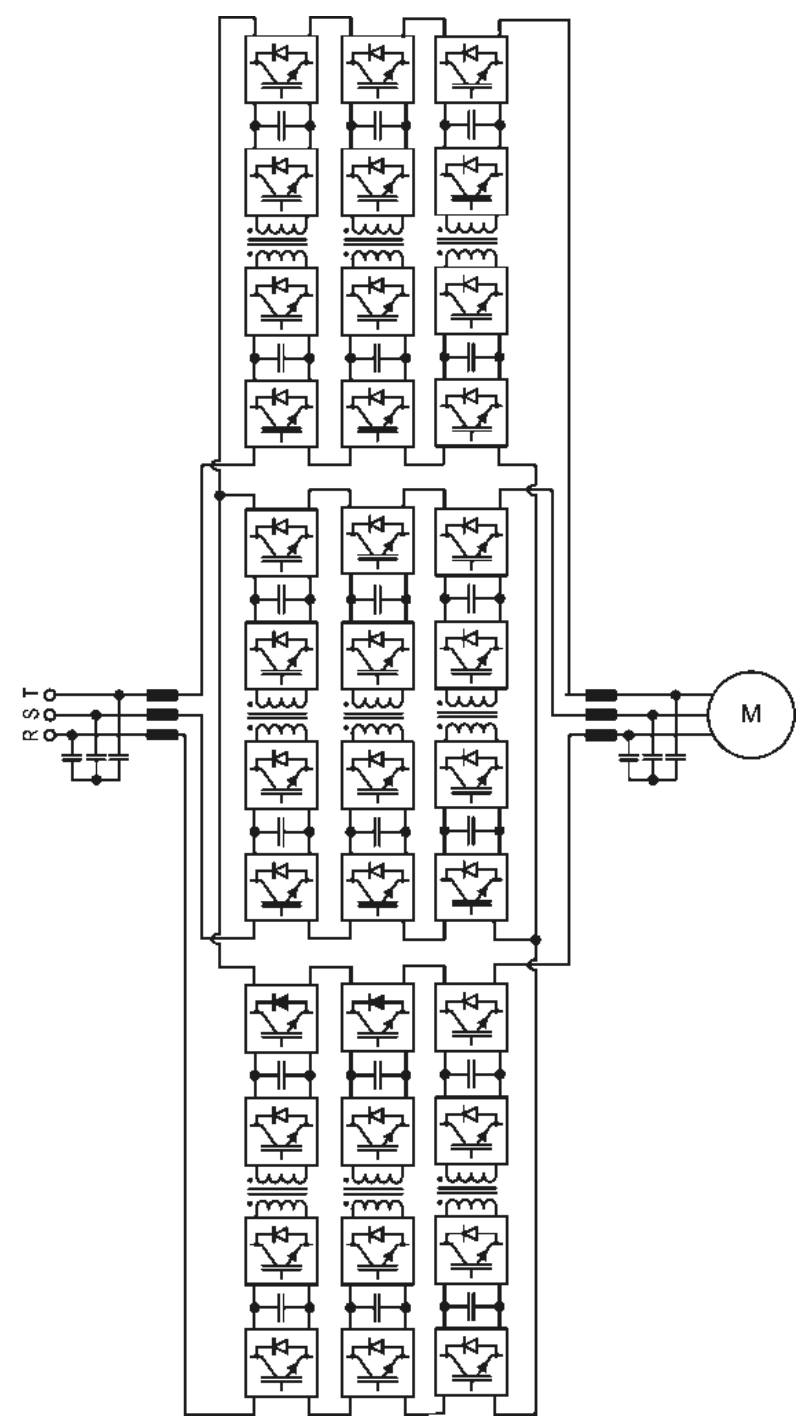

Fig. 1. The overall scheme of $0.6 \mathrm{MW}, 3.3 \mathrm{kV} / 3.3 \mathrm{kV}$ PET installed in the oil well [13].

The active front-end stage creates a near sinusoidal waveforms that require no filtering. The multilevel cascaded full-bridge PWM converter ensures total harmonic distortion (THD) below 4\% [12]. Application of $1.7-\mathrm{kV}$ IGBTs allows the isolated modular multilevel power converter to get high efficiency and high power density of magnetic components and line filters compared to $6.5 \mathrm{kV}$ or $3.3-\mathrm{kV}$ IGBT-based counterparts. The cleaner, spike free power being delivered by the PET converter along the long cable to the asynchronous motor installed from $2 \mathrm{~km}$ to $5 \mathrm{~km}$ underground helps to ensure the longest possible ESP run life by minimizing the degradation of the ESP electrical system insulation [12]. The PET converter having NEMA-4 enclosure to protect against windblown dust and water, occupies twice smaller deck space than existing LV drives supplied from line frequency transformers and is capable of uninterrupted operation at high summer temperatures of up to $55^{\circ} \mathrm{C}$.

Application of fast switching $1.2-\mathrm{kV} \mathrm{SiC} \mathrm{MOSFETs,}$ enables the PET-based variable speed drives to obtain improved functionality. Fig. 2. Shows SiC-based successor of PET from Fig. 1. The increase in frequency of HFTs from $8 \mathrm{kHz}$ to $25 \mathrm{kHz}$ allows noiseless operation of the PET and HFTs downsizing. The 1MW, $4 \mathrm{kV} / 4 \mathrm{kV}$ PET, shown in Fig. 2, has been constructed from 1.2-kV SiC MOSFETs and consists of six cascaded cells in each phase.

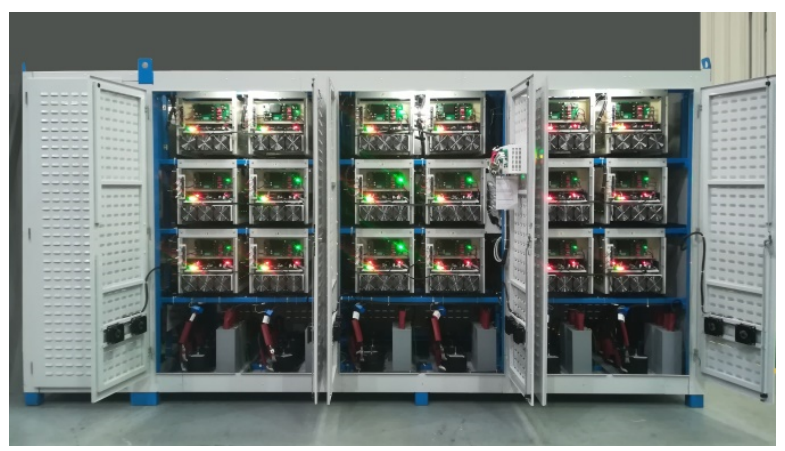

Fig. 2. Air-cooled $4 \mathrm{kV} / 4 \mathrm{kV}$ PET, constructed from $1.2 \mathrm{kV} \mathrm{SiC}$ MOSFET power modules (Photo courtesy of MMB Drives )

\section{Novel autotransformer-based PETT for multi-system EMUs}

Replacement of bulky $6.5 \mathrm{kV}$ IGBTs by SiC-based counterparts in the PETT system from [10] will not completely eliminate the problem of limited frequency of HFTs. High-voltage SiC devices suffer from high $\mathrm{dv} / \mathrm{dt}$ and di/dt slew rates required to limit the switching losses. Fast $1.2 \mathrm{kV} \mathrm{SiC-MOSFETs} \mathrm{give} \mathrm{more} \mathrm{freedom}$ and the ability to design a noiseless device with less EMI emissions. First of all the DC-AC PETT for $3 \mathrm{kV}$ DC traction is proposed. The overall scheme of the compact traction converter combining multilevel propulsion inverter and auxiliary power converter in the same housing is shown in Fig. 3. The proposed PETT topology consists of: (i) filter inductor, (ii) cascaded connection of isolated DC-DC converters including input filter capacitors and HFTs operated with high frequency, above $20 \mathrm{kHz}$, (iii) the three phase propulsion inverter realized as cascaded full-bridge multilevel converter and (iv) integrated auxiliary converter.

The propulsion inverter features a cascaded fullbridge multilevel DC-AC converter topology. Each phase of the propulsion inverter consists of three fullbridges connected in series. A cascaded topology having 3 isolated input sources in each phase provides 7 levels to synthesize the AC output voltage waveform. This 7level voltage waveform enables significant reduction of harmonics in the synthesized output current feeding the traction motor. The high frequency isolated dual active bridge (DAB) converters galvanically separate the propulsion inverter and auxiliary power converter from traction grid. In the PETT from Fig. 3 the DC traction voltage $u_{d c}$ is divided between five DC-link capacitors of DAB DC-DC converters. 


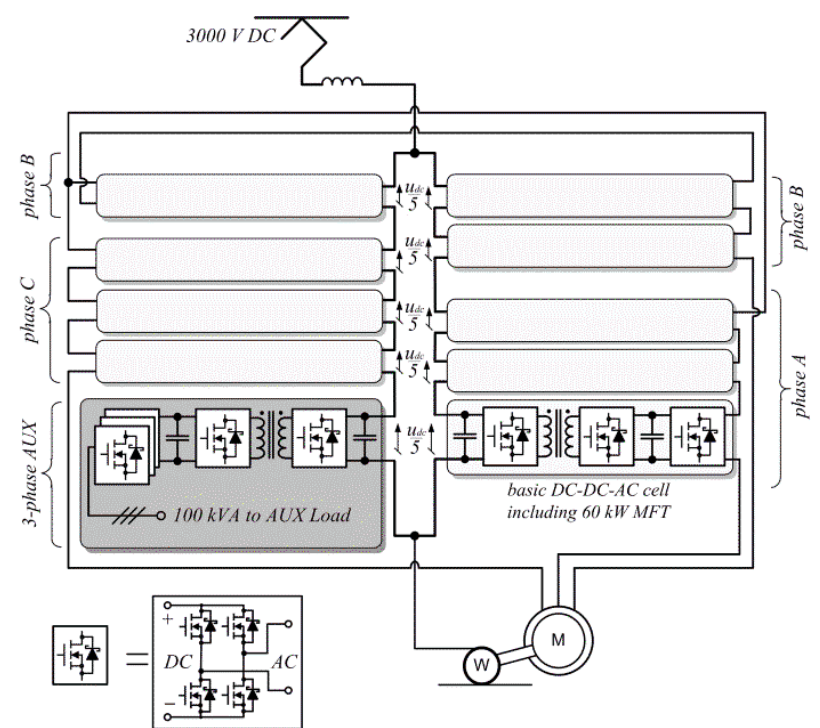

Fig. 3. The proposed DC-AC PETT

One fifth of the actual DC traction voltage is connected to each DAB converter. Five DAB DC-DC converters connected in series, step up or down the input voltage voltages during voltage transients in DC traction line. Two sets of DC-DC-AC converters operate within the compact traction power converter. As the propulsion inverter use 9 isolated power cells, the one remaining isolated DAB DC-DC converter serve as isolating stage for the $3 \times 400 \mathrm{~V}$ auxiliary power converter. The concept the traction converter shown in Fig. 3 can be extended to multi-system version. The replacement of the isolated DC-DC-AC cells with four quadrant isolated AC-DCDC-AC counterparts is therefore required. The inherent galvanic isolation of the traction converter from Fig. 3 can be utilized in multisystem converter for galvanic isolation from $\mathrm{AC}$ traction grid. To cope with the problem of connection of PETT with the AC traction voltage $(15 \mathrm{kV}$ or $25 \mathrm{kV})$, a low-frequency autotransformer, shown in Fig. 4, is proposed. According to the proposed concept, the four quadrant isolated AC-DC-DC-AC cells, connected in cascade, form the three-stages of the PETT: $(i)$ the single phase multilevel cascaded full-bridge rectifier connected to the voltageadjusting autotransformer, (ii) isolated DC-DC stage and (iii) three phase multilevel cascaded full-bridge propulsion inverter integrated with auxiliary power converter.

The concept of the autotransformer-based traction converter for the multisystem EMUs is shown in Fig. 5.

The advantages of the proposed system are: expected lower weight of the LF autotransformer when compared to HFT, lower costs, increased reliability and flexibility and preferably lower complexity when compared to existing PETT [10]. The design and optimization of the line frequency adjusting autotransformer is out of scope of the present paper and will be described in further publications.

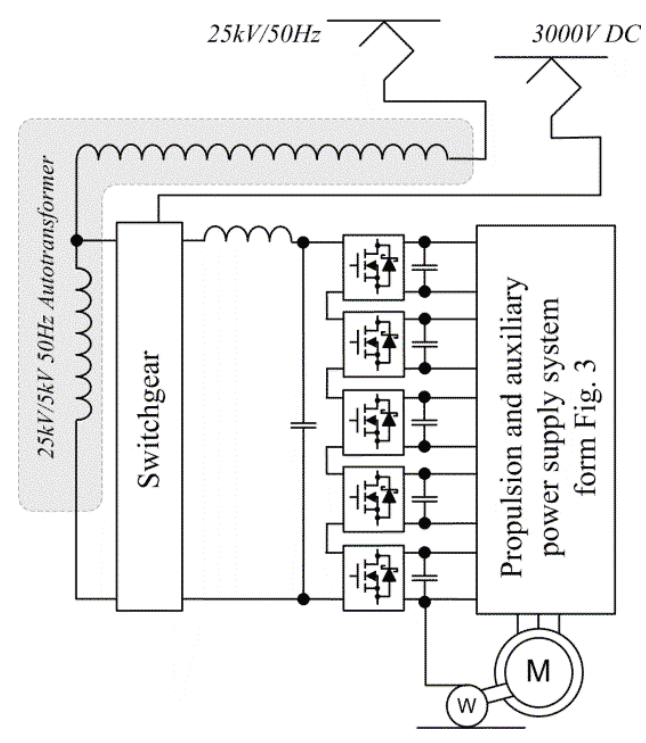

Fig. 4. Functional scheme of the proposed autotransformer-based traction converter

\section{SiC-based Dual Active Bridge converter as a key component of PETT}

The key component of the proposed PETT, which is the isolated DAB DC-DC converter (Fig. 5), has been investigated experimentally.

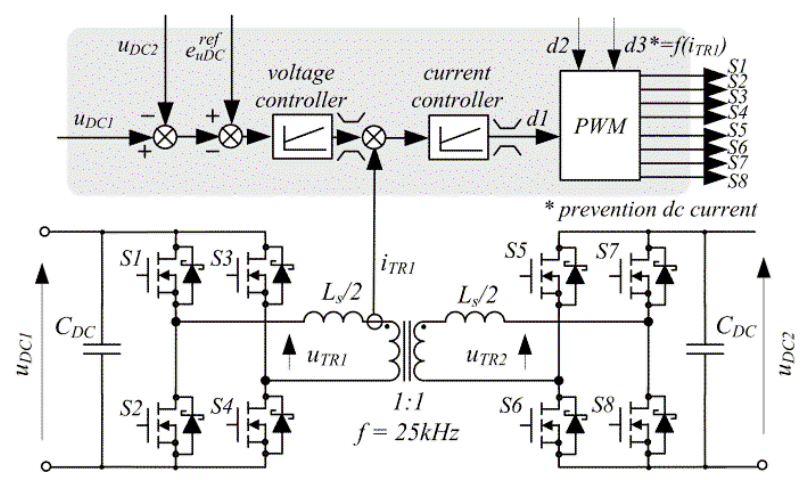

Fig. 5. Isolated dual active bridge DC-DC converter under investigations.

The $400 \mathrm{~kW}, 2340 \mathrm{~V}$ asynchronous traction motor has been assumed for further investigation. According to the maximum power of $500 \mathrm{~kW}$, the nominal power of the designed DAB DC-DC converter is about $60 \mathrm{~kW}$. The investigated $\mathrm{DAB}$ converter from Fig. 5 has been built from CAS120M12BM2 power modules characterizing continuous drain current of 138A at 90 Celsius degrees. The DAB DC-DC converter enables bi-directional power flow which is controlled using phase shift control. The DC voltages: $u_{D C 1}$ on primary side and $u_{D C 2}$ on secondary side are converted into high frequency rectangular pulses, with constant or modulated pulse width. 
The transferred power depends on the mutual phase shift $d_{l}$ ratio between primary and secondary voltages $u_{D C l}$ and $u_{D C 2}$. For pure phase-shift control, when the voltage pulse duty cycle is fixed at $50 \%$, the transferred power is described by the following relation:

$$
P=\frac{u_{D C 1} \cdot u_{D C 2}}{2 \cdot f \cdot L_{s}} \cdot d_{1} \cdot\left(1-d_{1}\right)
$$

where $\mathrm{f}=25 \mathrm{kHz}$ denotes switching frequency of the $\mathrm{SiC}$ MOSFETs. Fig. 8 shows the output power as a function of the phase shift $d_{l}$. For dual phase-shift control voltage pulse width can be adjusted second phase shift parameter $d_{2}$ between pair of switches $S_{i}, S_{i+2}$ (Fig. 5), $i=1,2,5,6$. Phase shift $d_{2}$ modulates the voltage pulse width and can be used for shaping of the transformer current (loss minimization) and for prevention from the core saturation.

Fig. 6 shows the characteristic waveforms of DAB converter: the secondary transformer voltage $u_{T R 2}$, secondary transformer current $i_{T R 2}$ (inverted) and voltage of $S_{2}$ with half load (30kW). The commercially available high frequency $100 \mathrm{~kW}$ transformer (oversized) with N87 UIIU/93/245/30 core has been used in the first experiment. Two identical series inductors $L S / 2=10 \mu \mathrm{H}$ consisting of ferrite cores and Litz wires were connected to the transformer to adjust the inductance value Ls which affect the power flow. A significant ringing can be observed in the transformer voltage and current. It can be deduced that their magnitude will increase with increased power. For the second experiment an optimized high frequency transformer has been designed within the present project. Litz wire coils, N87 core material and insulation resin with optimized temperature conductivity coefficient have been used in the design. Fig.7 shows characteristic waveforms of $60 \mathrm{~kW}$ DAB converter at half load: secondary transformer voltage $u_{T R 2}$, secondary transformer current $i_{T R 2}$ and $S_{1}$ switch voltage. The ringing in transformer voltage and current have been reduced significantly. The measured $\mathrm{dv} / \mathrm{dt}$ value during $\mathrm{SiC}$ transistor switching in Fig. $7 \mathrm{~b}$ is $3.5 \mathrm{kV} / \mu \mathrm{s}$ and the basic frequency of the $\mathrm{SiC}$ transistor voltage oscillations is $30 \mathrm{MHz}$. Fig. 9 and Fig. 10 show the results of the temperature test. The investigated $\mathrm{DAB}$ converter operated with full load of $60 \mathrm{~kW}$.

\section{Conclusions}

The concept of novel autotransformer-based PETT for multi-system EMUs was proposed. The investigated SiC-based PETT features noiseless operation and galvanic isolation realized with the use of highfrequency transformers. Special attention was given on isolated DAB DC-DC converter, which provides power flow control with high efficiency.

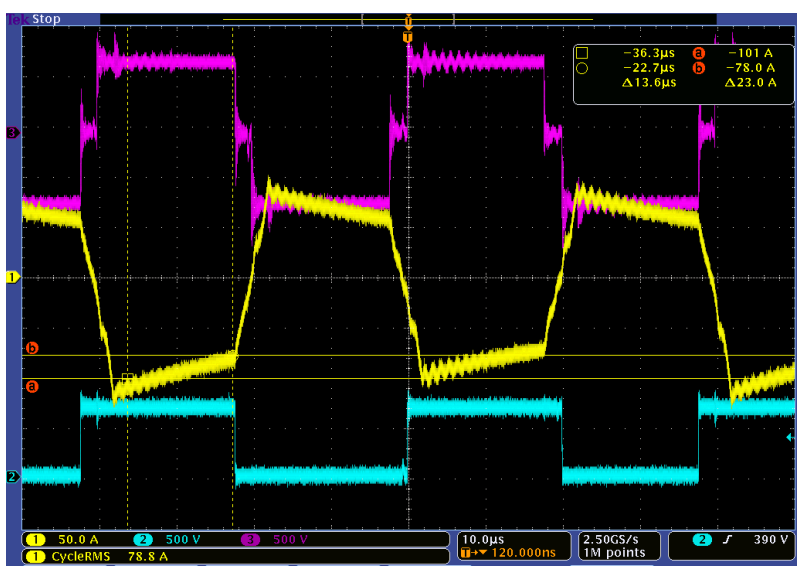

Fig. 6. Characteristic waveforms of $\mathrm{DAB}$ converter with commercially available high frequency transformer at half load $(30 \mathrm{~kW})$.

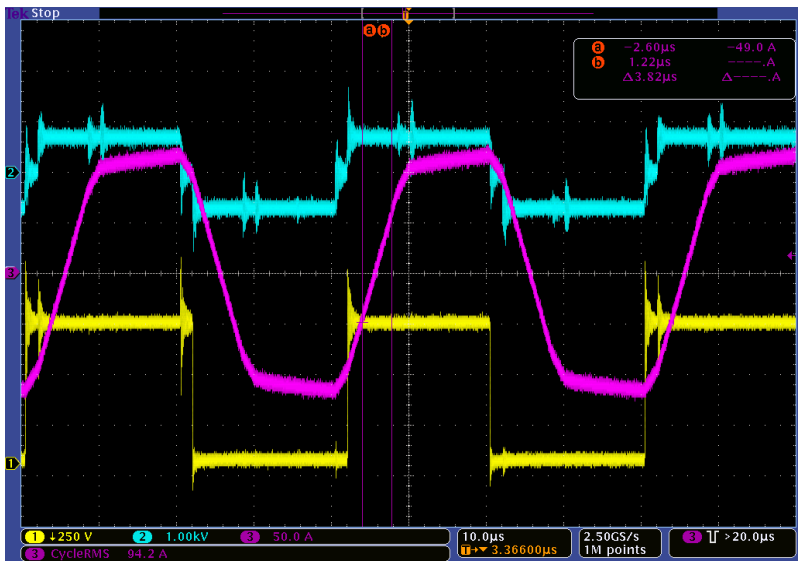

a)

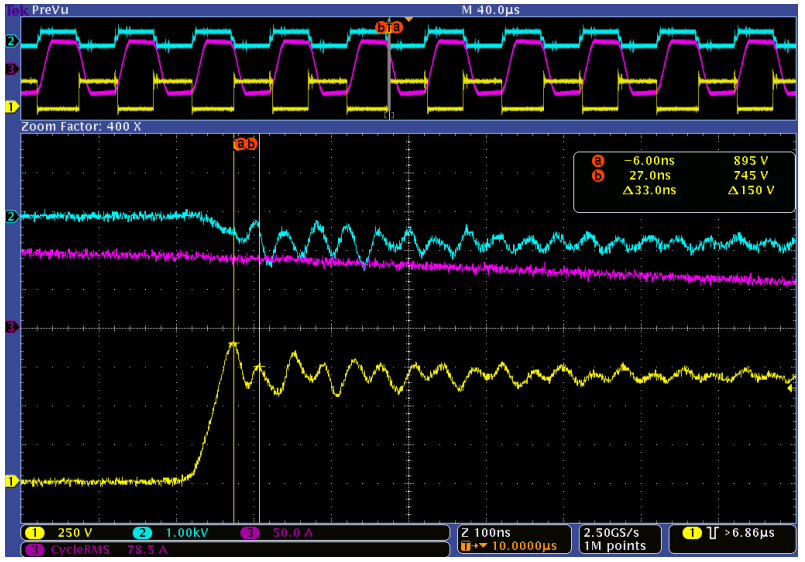

b)

Fig. 7. Characteristic waveforms of DAB converter with $60 \mathrm{~kW}$ HFT optimized for the project, at half load (a) and transients during SiC switching (b).

The investigated isolated DAB DC-DC converter, constructed from $1.2 \mathrm{kV} \mathrm{SiC} \mathrm{MOSFETs} \mathrm{demonstrates}$ $60 \mathrm{~kW}$ transferable power using $25 \mathrm{kHz}$ switching frequency. The measured temperature of heatsinks did not exceed 55 Celsius degrees during constant load operation, which is a promising result when taking into account application in roof-mounted container. 


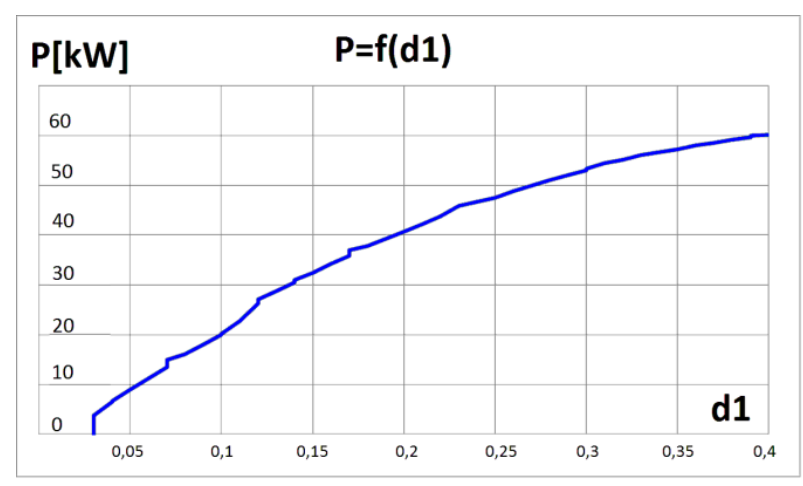

Fig. 8. Output power in function of phase shift $\mathrm{d} 1$.

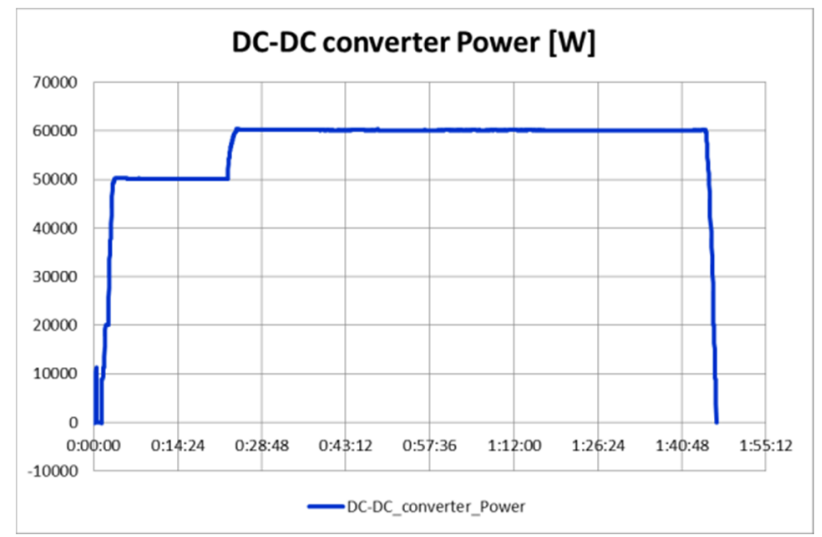

Fig. 9. Output power during temperature test.

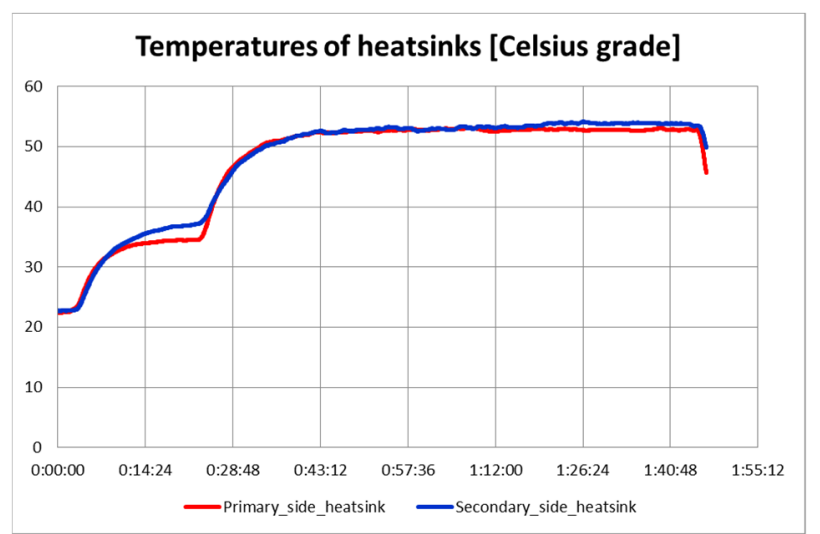

Fig. 10. Temperatures of DAB heatsinks.

The next step of investigations should be detailed EMC analysis on compliance with railway standards.

This scientific work is financed from resources for science as a Research Project of the National Centre for Research and Development under agreement POIR.01.02.00-00-0193/16-00.

\section{References}

1. Drofenik U., Canales F., European Trends and Technologies in Traction, Proceedings International Power Electronics Conference IPEC, 1043-1049, (2014).
2. M. K. Das, SiC MOSFET Module Replaces up to $3 x$ Higher Current Si IGBT Modules in Voltage Source Inverter Application, Bodo's Power Systems, 2, 2224, (2013), www.bodospower.com

3. Pala V., van Brunt E., Casady J., Simplifying power conversion with medium voltage SiC MOSFETs, Compound Semiconductor, 3, 44-47, (2016),

4. Negeshi T., Tsuda R., Ota K., Iura S., Yamaguchi H., 3.3-kV All-SiC Power Module for Traction System Use, Proceedings Int. Conf. PCIM Europe, 51-56, (2017)

5. Mitsubishi electric corporation news releases No.2942, Mitsubishi Electric Installs Railcar Traction System with All-SiC Power Modules on Shinkansen Bullet Trains, June, 25 (2015)

6. BORDLINE® CC1500 MS. High power multisystem propulsion converter, Product data sheet, ABB (2012)

7. Vetterli C., Suranyi A., Concept et potentiel d'économie d'énergie d'un transformateur de traction électronique "PETT", Rapport annuel, ABB Sécheron SA (2013)

8. Chamaret A.P., Frugier D., Future of on-board traction transformer for rolling stock, Proc. 11th World Congress of Railway Research, 1-6, (2016)

9. Huber J. E., Kolar J.W., Optimum Number of Cascaded Cells for High-Power Medium-Voltage $A C-D C$ Converters, IEEE Journal Emer. Select. Top. Power Electr., 5(1), 213-232, (2017)

10. Zhao C., Dujic D., Mester A., Steinke J.K., at al.: Power Electronic Traction Trans-former-Medium Voltage Prototype, IEEE Transactions on Industrial Electronics, 61(1), 3257-3268, (2014)

11. Adamowicz M., Krzemiński Z., Multi-system locomotive feeding system, Polish Patent No PL $226553 \mathrm{~B} 1$

12. Orlowski T., Radcliffe Alan R., Application of New Generation Variable Speed Drive Solutions To Reduce Footprint and Operating Cost, Proceedings SPE Middle East Artificial Lift Conference, 1-9, (2016)

13. Adamowicz M., Krzemiński Z., Medium voltage (MV) modular multilevel converters, Automatyka Elektryka Zakłócenia, 5(3), 56-71, (2014) in Polish, available online.

14. Inoue S., Akagi H., A Bidirectional Isolated DC-DC Converter as a Core Circuit of the Next-Generation Medium-Voltage Power Conversion System, IEEE Transactions On Power Electronics, 22(2), 535-542, (2007)

15. Lewicki A., DC-link voltage balancing in cascaded H-Bridge converters, Archives of Electrical Engineering, 63(3), 439-455, (2014) 